\title{
Clinical governance and continuing professional development
}

\author{
John Wattis \& Peter McGinnis
}

Clinical governance can be defined as:

"a framework through which NHS organisations are accountable for continuously improving the quality of their services and safeguarding high standards of care by creating an environment in which excellence in clinical care will flourish" (NHS Executive, 1998).

Continuing professional development (CPD) :

"ensures the best quality of patient care within the facilities available by [clinicians] keeping up-to-date with current knowledge, learning new material, practising clinical skills with proficiency and developing new ones" (Royal College of Psychiatrists, 1997).

Like clinical governance, CPD is a continuous process that involves an element of monitoring and feedback. Both clinical governance and CPD share the aim of achieving excellence in clinical care; however, the former aims to create the conditions in which clinical excellence can flourish, and the latter to develop personal competencies or capabilities for the same end.

\section{Managers, doctors, governance and development}

Some would argue that management and medicine, especially psychiatry, have a great deal in common. For a reasonable chance of success both require a high level of knowledge, skills in working with people and positive attitudes. Both also require knowledge and skills to be applied in complicated situations where there is no 'right' answer. Evidence- based practice is possible in management as well as in medicine, although the type of evidence used in management would rarely meet the specifications of the randomised double-blind placebo-controlled trial. It is even possible to apply evidence-based principles to policy-making, although there is as yet precious little evidence of this in health policy. Making the National Health Service (NHS) work better requires a great deal of clarity and honesty in understanding the problems that currently exist. Governance implies a duty to ensure quality and a system for achieving this. Continuing professional development implies a process of positive change for the individuals who deliver that quality service. Before going on to consider the relationships between clinical governance and CPD in more detail, we will consider some of the background in terms of management theory and the politics of recent problems in the NHS.

\section{Management theory}

Different 'metaphors' of management are brilliantly analysed in the book Images of Organization (Morgan, 1997). Morgan argues that metaphors provide powerful but one-sided insights into what happens in organisations. The metaphors he lists include organisations as: machines; organisms; brains; cultures; political systems; psychic prisons; flux and transformation; and instruments of domination.

Three metaphors will be further explored here, in the context of clinical governance and CPD. The first

John Wattis is a consultant and senior lecturer in old age psychiatry and became Medical Director of Leeds Community \& Mental Health Services over three years ago (The Mansion, Meanwood Park Hospital, Tongue Lane, Leeds LS6 4QB). Peter McGinnis is Director of Nursing and Quality. They have an interest in knowledge management and shared governance, and in ensuring managers and clinicians understand each others' pressures, viewpoints and priorities. 
two are from Morgan's list: organisations as cultures and organisations as political systems; the third is the metaphor of organisations as guardians and developers of intellectual capital. This metaphor is closely related to the metaphor of organisations as brains. Knowledge management is a growing body of knowledge about how to get the best out of organisations which largely depend on knowledge (intellectual capital) for their success or failure.

\section{Organisations as cultures}

The metaphor of organisations as cultures is expounded most popularly by Charles Handy in the book Gods of Management (Handy, 1995). Handy identifies four main cultures which he labels with the names of Greek Gods. Zeus represents the 'club' culture - thinks intuitively, changes things by personal influence and control of resources, and is motivated by making a difference. Apollo represents the 'role' culture - thinks sequentially, changes things by exercising authority within a framework of roles and rules, and is motivated by duty. Athena represents the 'task' culture - thinks pragmatically, changes things by problem-solving (often in teams), influences by wisdom and expertise, and is motivated by the satisfaction of solving problems. Dionysus represents the 'existential' culture - thinks in a variety of ways, wants to be 'the best', is difficult to predict and is motivated by personal success and professional freedom.

This is a very simple exposition of the metaphor of cultures, but it is hard to resist the notion that one of the main problems of health service management has been cultural incompatibility between 'role' culture (bureaucratic) managers and 'task' - centred or 'existential' professionals (Wattis, 1996). This is important for clinical governance because corporate governance, on which clinical governance is modelled, depends essentially on a system of bureaucratic controls. If politicians and civil servants attempt (Zeus-like) to impose this model of governance, culturally inappropriate systems will result. It is implicit in Handy's analysis that an organisation may contain elements of all the different cultures above (and other variants) and still be successful. The trouble arises either when part of the organisation does not have a culture appropriate to the job it is doing, or when one part of the organisation does not recognise the important differences that exist and tries to force inappropriate solutions on another. We need 'club' culture people to make things happen at higher levels of the organisation. We need 'role' culture people to ensure that we have our wages paid regularly with the appropriate deductions; we also need them to build information systems to support clinical practice. We need 'task' culture clinicians and operational managers to pragmatically solve the problems that arise in clinical practice and in the everyday life of organisations. We need the creativity of the 'existential' approach.

\section{Organisations as political systems}

This is another powerful metaphor particularly pertinent to the issue in hand. We tend to think of politics in a derogatory way: it is seen to be concerned with power and manipulation. In fact, politics is a way of allowing the divergent needs and aspirations of individuals in a society to work together for the common good without oppression or bloodshed. There are many different models of government for organisation, but four of these have some links with the cultures discussed above and are listed in Box 1.

\section{Intellectual capital and knowledge management}

The history of knowledge management lies in the realisation that the value of many companies on the

Box 1. Four different models of government for organisation

Autocracy: found sometimes in firms owned by an individual or family. Watchphrase: 'We'll do it this way because I say so.' (perhaps also found in traditional medical 'firms')

Bureaucracy: the typical way of large organisations in stable situations. Watchphrase: 'The rules say this is the way to do it follow the agreed procedures'

Technocracy: typically the culture of experts working in problem-solving teams. Watchphrase: 'Let's try to do it this way-evidence and experience lead us to believe this is best.'

Democracy: in this sense, a situation where everybody has a say, and a consensus is sought. Watchphrase: 'Let's see what everybody wants to do about this.' Or even (deteriorating into anarchy): 'I'll do it my way' 
stock exchange is many times the value of their tangible assets. This was attributed to knowledge assets or 'intellectual capital'(Stewart, 1997). Successful companies were those which managed this intangible aspect of the business well. The NHS is a wonderful example of an organisation which depends on knowledge for its value, but traditionally has not recognised the importance of that knowledge in its management structures or organisational styles. The added value we could achieve in the NHS - if we started to manage knowledge properly and based practice on best evidence - would be stunning. Knowledge assets within the NHS can be categorised into human, structural and customer capital, and defined as follows (summarised in Box 2).

Human capital can be defined as the capabilities of the individuals required to provide solutions to customers. In the NHS, this is exemplified by the skills and knowledge of clinical staff, and is precisely what CPD is intended to protect and develop.

Structural capital can be defined as the capabilities of the organisation to meet market requirements. This includes good-quality buildings from which to practice, but more importantly than that, it includes access to information. This information has three main strands: information about good practice, information about individual patients, and information about activity and performance. The new Department of Health consultation paper about information in the NHS (Burns, 1998) suggests that the relationship between access to information and clinical effectiveness has at last been recognised centrally. This is just as well, since the investment in information technology to achieve the aims of clinical governance will need to be extensive (Black, 1998).

Customer capital is defined as the value of an organisation's relationships with the people with whom it does business. For psychiatrists working in the NHS, this includes NHS trust and personal relationships with health authorities, general practitioners, social services, housing departments,

Box 2. Knowledge assets within the NHS

Human capital: the capabilities of the individuals required to provide solutions to customers

Structural capital: the capabilities of the organisation to meet market requirements

Customer capital: the value of an organisation's realtionships with the people with whom it does business other parts of the NHS and, most importantly, patients and carers.

Knowledge management is a metaphor that enables people from different organisational cultures to sign up to a common goal. The emphasis on human capital satisfies the 'task' and 'existential' cultures that predominate in clinical practice; the emphasis on structural capital finds a place for those most comfortable with the 'role' culture; and the recognised importance of customer capital gives a boost to the networking tendencies of the 'club' culture. This emphasises the need for a 'collective partnership' of all the cultures in the NHS to achieve success.

\section{Recent problems}

The recent problems in professional self-regulation present the backdrop to the introduction of clinical governance. The Bristol case, involving the emotive issue of children's deaths following heart surgery, has stoked up political resolve to ensure that doctors in particular, and clinicians in general, are properly regulated (or governed). Following this case, there have been debates about issues of supervision and the Standing Committee on Postgraduate Medical Education (SCOPMED) has been moved to issue a report (SCOPMED, 1998) emphasising the differences between mentoring and monitoring, which were apparently overlooked in the NHS White Paper.

The wider context for the introduction of clinical governance includes the acknowledged limited success of clinical audit (Berger, 1998) and the clinical effectiveness movement, problems in implementing the Care Programme Approach (Burns, 1997), and the apparently intractable problem of bridging the gap between theory, evidence and practice (Howard et al, 1996; Timpson, 1996).

A project sponsored by the NHS Executive, 'Action on Clinical Audit', is currently investigating the problems in clinical audit and attempting to overcome them (Berger, 1998). Problems already identified in some NHS trusts include a lack of boardlevel committment to clinical audit and a difference in views about priorities in clinical audit between managers and clinicians. This is reflected in difficulties in establishing information systems which truly serve the needs of patients and clinicians as well as those of accountants and managers. Unrealistic assumptions about the resources needed to implement clinical audit, in the face of competing pressures from clinical work, should not be repeated for clinical governance.

An almost exclusive emphasis on financial management has made it difficult for health service managers to maintain an effective focus on other 
issues. At the same time, the wider business community and some NHS trusts have been increasingly aware of the need to maintain a 'balanced scorecard' (Kaplan \& Norton, 1998) in measuring performance.

\section{The NHS White Paper}

A First Class Service (NHS Executive, 1998) makes it clear that clinical governance needs to be seen in the context of the rest of the White Paper particularly the committment to national service frameworks (NSFs), of which mental health is to be one of the first; the National Institute of Clinical Effectiveness (NICE), which will effectively set standards for the NHS; and the Commission for Health Improvement (CHImp), which will perform a similar function to that of the Audit Commission but focusing on clinical effectiveness expressed in health outcomes, equity (access to services) and humanity (patients' and carers' views). The recently issued information strategy paper (Burns, 1998) also articulates a clear vision of the information infrastructure to support clinical governance.

A First Class Service describes a three-layered approach (see Fig. 1). The top layer (setting quality standards) involves the development of NSFs and standards for good clinical practice through NICE. The middle layer (delivering quality standards) has clinical governance as its central component, flanked by professional self-regulation and life-long learning (CPD). The final layer (monitoring quality standards) involves CHImp, a national framework for monitoring quality standards, and an annual national survey of patient and user satisfaction. Clinical governance sits at the centre of the new quality initiative.

\section{Components of clinical governance}

A First Class Service lists four main components of clinical governance (summarised in Box 3 ).

\section{Clear lines of responsibility and accountability for the overall quality of clinical care}

These are to be achieved by the NHS trust chief executive carrying ultimate responsibility for

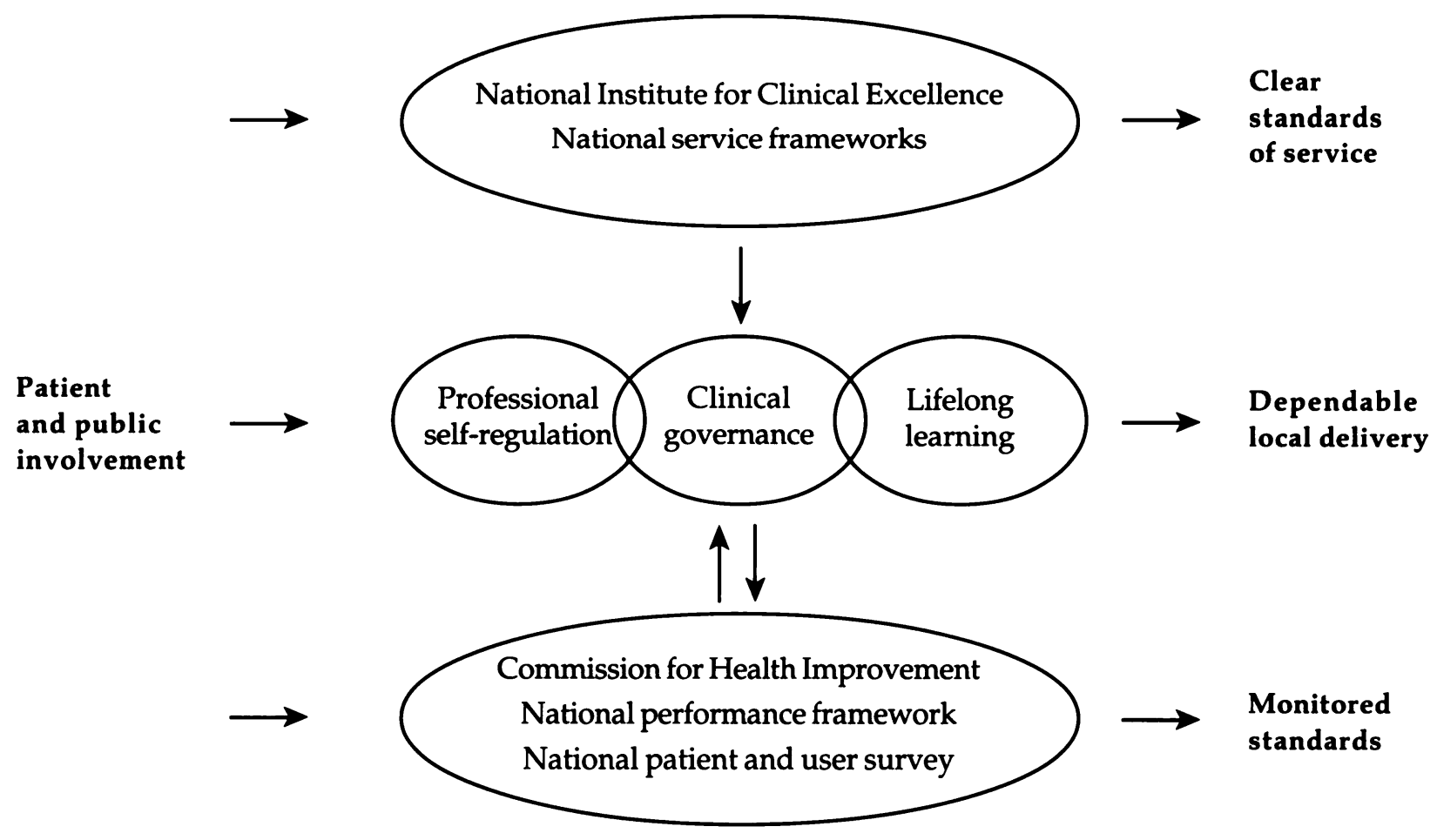


assuring the quality of services provided by the trust, by a designated senior clinician being responsible for clinical governance and by board-level involvement including regular reports and a formal annual report on clinical governance. Some will see this as a threat to the present process of professional selfregulation and it could be so. However, the main idea is to create systems for the improvement of clinical quality and to assure the board and the public that such systems exist and are effective. This is not a mechanism for dealing with individual problems, which is where self-regulation is so important. However, it attempts to ensure that those mechanisms are functioning by making the chief executive accountable.

\section{Comprehensive programme of quality improvement activities}

All doctors will be expected to participate fully in audit activities, including national audits endorsed by CHImp. Medical directors will be expected to discuss clinical audit results with individual practitioners. Full participation in the national confidential inquiries will be mandatory: for psychiatry in particular, this means the Confidential Inquiry into Suicide and Unexplained Deaths. Evidence-based practice will be supported and, ideally, applied routinely, and NSF and NICE recommendations will be implemented (according to A First Class Service). One is tempted to ask where the resources will come from. Workforce planning and development, we are told, will be fully integrated into service planning, and CPD programmes will be in place and supported locally. Confidentiality will be safeguarded in high-quality systems for clinical record-keeping, and clinical quality processes will be integrated with the quality programme for the whole organisation. These are noble intentions

Box 3. Four main components of clinical governance

Clear lines of responsibility and accountability for the overall quality of clinical care

A comprehensive programme of quality improvement activities

Clear policies aimed at manaing risk

Procedures for all professional groups to identify and remedy poor performance but again have considerable resource implications. They will need substantial investment in good, efficient, clinically focused information systems, in support staff and in medical, nursing and other clinical staff. Because of staff training, this will need time as well as money. If this latest government initiative is to be successful, the need for a genuine agreement by the politicians to provide the tools needed to do the job is vital. Clinical governance which emphasises accountability without providing essential resources is doomed to failure. Exhortations to Battle of Britain pilots to shoot down more Me 109s would have been worse than useless if they had only been flying First World War biplanes. They needed the Spitfires and Hurricanes as well as their training, dedication and skills to do the job.

\section{Clear policies aimed at managing risk}

A First Class Service proposes a 'controls assurance' approach to identify and manage clinical risks, coupled with systematic assessment of risk and risk reduction programmes. This means that the boards of trusts (and primary care groups) will need to be sure that robust policy and procedures exist for the assessment and reduction of risk. Unfortunately, doctors (apart from surgeons) are not very policy- or procedurally-minded. If we accept the inevitability of these changes, the potential benefits of working in partnership with nurses and others who are more used to implementing agreed procedures become evident.

\section{Procedures for all professional groups to identify and remedy poor performance}

Critical incident reporting, complaints procedures with an emphasis on 'lessons learned', and professional performance procedures will be implemented. Again, this is the language of the 'role' culture (or bureaucracy) and does not sit easily with traditional medical views on clinical autonomy. The need to support staff in their duty to report concerns is reiterated.

\section{Clinical governance into action}

Putting clinical governance into action requires a vision, a strategic framework, an operational 
system and a good deal of personal and professional development.

\section{Mission statements}

In common with other management approaches, knowledge management insists on a 'mission statement' which articulates the vision of the organisation. To work, this really must be agreed by everyone. In our context, this means politicians, civil servants, managers, general practitioners and those working in (and using) psychiatric services. Historically, mission statements in the NHS have had a bad track record because of organisational dishonesty and dissonance between stated and real aims. A mission statement ' $W e$ will provide a quality service for our patients', pinned to the crumbling walls of a Victorian ward staffed by overworked nurses reeks of dishonesty. This was especially true when the main (undeclared but omnipotent) mission of the NHS Executive was to control spending and avoid scandals at all costs. This dissonance between the overt and covert agendas of the NHS has been one of the prime causes of staff demoralisation. On the positive side, the emphasis on clinical governance, quality and equity in the NHS White Paper provides new hope. The definition of clinical governance - "to continuously improve the quality of NHS services and safeguard high standards of care by creating an environment in which excellence in clinical care will flourish" - needs perhaps to be balanced by some statement about financial limits, but otherwise contains most of the essentials of a mission statement for the NHS.

\section{A strategic framework}

The framework for clinical governance is already laid out in the NHS White Paper and in A First Class Service. Further guidance is to follow. Hopefully, NSFs will include some consideration of the resources needed. In considering the balance of resources needed in a particular service, the concept of 'safety zones' can be helpful. For example, the evidence of experience and some research suggests that a service which depends entirely on in-patient care or entirely on community care is not safe. What is needed is a balance between the resources in these areas - and that balance is best represented as a zone rather than a single point. Thus, a service with fewer beds would require proportionately more community resources; but all the community resources feasible could not compensate for a complete absence of beds.

\section{Shared governance}

In the recent history of the NHS, it could be argued that nurses and some other clinical professions, including psychologists, have been too much part of a 'role' culture. They have not been able to exercise enough freedom in developing their clinical practice, and have belonged to hierarchical structures where the only way to a higher pay packet was not clinical excellence but a move into management. On the other hand, consultants have been too autocratic (sometimes anarchic) and have valued 'clinical freedom' over the creation of systems to support good practice. Managers, on the whole, have belonged to 'role' cultures divorced from clinical practice, although the creation of clinical directorates has enabled some to bridge the gap. Shared governance (Porter-O'Grady, 1992) is a model which is neither controlled by managers nor clinicians, but is a true collaboration of both. It is a philosophy which accepts that managers and clinicians of all types cannot work effectively in isolation, and moves into the problemsolving arena of a 'team' culture. Decisions about effective clinical practice are made by those who are local to the clinical situation and have the expertise, clinical and managerial, to deliver good practice. Practice councils, formed from committed clinical leaders and managers, examine the evidence base to decide on deliverable best practice. In our vision, these councils are supported by a knowledge management infrastructure which enables them to access the best evidence and facilitates the training needed to make decisions work in practice.

\section{Role of CPD in clinical governance}

One could take the limited view that the role of CPD is simply in the 'box' of 'lifelong learning', alongside professional self-regulation in the middle layer of the structure proposed in A Fist Class Service. However, we would argue that while that is important, a far more vital use of CPD initially would be to develop clinicians' awareness and understanding of the issues facing health service managers, and vice versa. Without an underpinning understanding of the different tasks and cultures of managers and doctors, it is highly likely that some managers will try to use inappropriate methods to 'control' clinical performance, and some doctors will react negatively by fighting for their autonomy at any cost. This kind of 'bare knuckle fight' is what happens when neither side listens to the other. Continuing professional development should also consciously be used as a vehicle to develop psychiatrists' capacity to access, evaluate and use 
best evidence in collaboration with other clinicians and managers.

Further, it is vital that we return to principles of honesty in the public services, which have been so eroded by politicians constantly raising expectations of the health services without providing the resources to meet those expectations. This is bad politics as well as bad management since it leads to demoralisation, unnecessary conflict and reduced performance.

Perhaps we as psychiatrists, with our Royal College motto of 'let wisdom guide', should take the lead in organising seminars to be attended by equal numbers of clinicians and managers. These issues could be explored to enable everyone to get the greatest possible benefit from clinical governance. If we are proactive in taking clinical governance in this direction, we may prevent others foolishly trying to implement it by rules, regulations and inappropriate bureaucracy.

\section{References}

Berger, A. (1998) Why doesn't audit work? British Medical Journal, 316, 875-876.

Black, N. (1998) Clinical governance: fine words or action? British Medical Journal, 316, 297-298.

Burns, F. (1998) Information for Health: An Information Strategy for the Modern NHS 1998-2005. Leeds: NHS Executive.

Burns, T. (1997) Case management, care management and care programming. British Journal of Psychiatry, 170, 393395.

NHS Executive (1998) A First Class Service: Quality in the New NHS. London: Department of Health.

Handy, C. (1995) Gods of Management: The Changing Work of Organisations (3rd edn). London: Arrow Business Books.

Howard, E. P., Beachesne, M. A., Shea, C. A., et al (1996) Research practicum: linking education to practice. Nursing Education, 2, 33-37.

Kaplan, R. \& Norton, D. (1998) The Balanced Scorecard: Translating Strategy into Action. Boston, MA: Harvard Business School.

Morgan, G. (1997) Images of Organization (2nd edn). London: Sage.

Porter-O'Grady, T. (1992) Implementing Shared Governance: Creating Professional Organization. St Louis, MO: Mosby.

Royal College of Psychiatrists (1997) Policy for the Continuing Professional Development of Psychiatrists (Council Report CR58). London: Royal College of Psychiatrists.

Standing Committee on Postgraduate Medical and Dental Education (1998) An Enquiry into Mentoring: Supporting Doctors and Dentists at Work. London: SCOPMED.

Stewart, T. A. (1997) Intellectual Capital: The New Wealth of Organizations. London: John Wilson.

Timpson, J. (1996) Nursing theory: everything the artist spits is art? Journal of Advanced Nursing, 23, 1030-1036.

Wattis, J. P. (1996) Jostling for rank in the god squad. Health Seroice Journal, 106, 27.

\section{Multiple choice questions}

1. Clinical governance:

a will make doctors follow strict protocols in treating patients

b will make chief executives responsible for clinical quality in trusts

c can be implemented effectively without additional resources

d will require clear policies aimed at managing risk

e has no relationship to continuing professional development.

2. Clinical governance:

a removes the need for professional selfregulation

b means regular reports to trust boards about the performance of individual clinicians

c will require all doctors to participate fully in clinical audit

d will require medical directors to discuss audit results with individual doctors

e will replace national confidential inquiries.

3. Clinical governance will work best:

a if managers develop bureaucratic controls over the actions of doctors

$\mathrm{b}$ if clinicians of all disciplines and managers work together to agree standards for practice

c if managers are not involved

$\mathrm{d}$ if doctors are not involved

e where there is mutual respect and understanding between clinicians and managers.

$\mathrm{MCQ}$ answers

$\begin{array}{lllll}\text { I } & \text { 2 } & \text { 3 } \\ \text { a F } & \text { a F } & \text { a F } \\ \text { b T } & \text { b } \text { T } & \text { b } \text { T } \\ \text { c F } & \text { c T } & \text { c F } \\ \text { d T } & \text { d T } & \text { d F } \\ \text { e F } & \text { e F } & \text { e T }\end{array}$

